\title{
The Generation in Between: A Perspective from the Keystone IV Conference
}

\author{
Frederick M. Chen, MD, MPH, Erika Bliss, MD, Aaron Dunn, MD, \\ Jennifer Edgoose, MD, MPH, Tricia C. Elliott, MD, Lisa C. Maxwell, MD, \\ Carl G. Morris, MD, MPH, and Robert L. Phillips, Jr., MD, MSPH
}

Keystone IV affirmed the value of relationships in family medicine, but each generation of family physicians took away different impressions and lessons. "Generation III," between the Baby Boomers and Millennials, reported conflict between their professional ideal of family medicine and the realities of current practice. But the Keystone conference also helped them appreciate core values of family medicine, their shared experience, and new opportunities for leadership. ( $\mathrm{J}$ Am Board Fam Med 2016;29: S49-S53.)

Guest editors' note: This Article was prepared after the G. Gayle Stephens Keystone IV Conference by authors from the "sandwich" generation of conference attendees, specifically, midcareer individuals immersed in the mismatch of what it takes to get through the day, what patients need from their personal physicians, and what personal physicians need to keep the promises they want to make.

Keywords: Doctoring, Family Medicine, Family Physician, Health Care Delivery, Personal Physician, Population Health, Primary Care, Professionalism, Social Justice

In 2015, the Keystone IV Conference culminated in a reaffirmation of the unifying concept of relationship in family medicine. Charged with exploring the meaning of place and time in family medicine, attendees kept coming back to the central engagement in family medicine: the interpersonal relationship. From the youngest to the most senior participants, relation-

This article was externally peer reviewed.

Submitted 29 December 2015; revised 13 April 2016; accepted 19 April 2016.

From the Department of Family Medicine, University of Washington School of Medicine, Seattle (FMC); Qliance, Seattle, WA (EB); Dean Clinic, Mineral Point, WI (AD); the Department of Family Medicine and Community Health, University of Wisconsin, Madison (JE); the Department of Family Medicine, University of Texas Medical Branch, Galveston (TCE); Christiana Care Family Medicine, Wilmington, DE (LCM); Group Health Family Medicine Residency, Seattle, WA (CGM); and the American Board of Family Medicine, Lexington, KY (RP).

Funding: none.

Conflict of interest: none declared.

Corresponding author: Frederick M. Chen, MD, MPH, Department of Family Medicine, University of Washington School of Medicine, 4311 Eleventh Ave NE, Ste. 210, Seattle, WA 98105 (E-mail: fchen@uw.edu). ship resonated with our chosen profession. Not surprisingly, the central focus of healing is an intimate bond between 2 people, sealed by relationship and enabled by medicine and illness.

However, the personal meanings of the conference differed among participants. The experience of relationship and family medicine can evolve from recent residency graduates to those who have practiced in the same town for decades. Part of the difference in meaning is simply a function of time and age. In keeping with the historic Keystone generational construct, we examined the impressions, experiences, and lessons learned from "Generation III" of family medicine, also identified as Generation X, born between 1965 and 1980, they are temporally sandwiched between the Baby Boomers and Millennials. ${ }^{1}$

\section{Methods}

Using an iterative in-depth interview technique, we solicited answers to 3 specific questions from select Generation III participants at Keystone: 
1. How do you define your current life experience being a family doctor and personal physician?

2. What memories, themes, lessons have remained with you from Keystone?

3. How have you used Keystone in your current work?

After compiling and transcribing the initial responses, common themes emerged. These themes were then reflected to the entire group of respondents and further refined. Individual participants are quoted but not identified.

\section{Results}

\section{The Generation in Between}

This generation identifies a tangible sense of being in between 2 distinct generations, particularly as defined by both technology (between dictation and handwriting and the electronic medical record [EMR]) and sociodemographics (between Baby Boomers and Millennials).

- "We were residents before duty hour regulations so have a different work ethic than Millennials."

- "We grew up with the implementation of the computer and the EMR. We went from bringing a typewriter to college to starting our first practice with implementation of an EMR. Since then we have adapted and grown with the various versions of electronic communication-EMR, secure messaging, telephone visits. While not being an expert in technology, we do not fear it and are able to make wise choices about adopting the changes that are most useful. When the EHR goes down, we know how to write SOAP notes."

- "We fall somewhere in between regarding social media. Many of us are dabblers using it strictly for social purposes, not for business applications, marketing, patient resources, etc."

- "Many of us rode the health maintenance organization [HMO] wave of primary care promise, and while we learned to speak about the value of primary care, some of us are deflated by the failure of that promise and, as a result, can be skeptical about the latest primary care emphasis. We also entered our careers on the downside of the "golden age" of medicine in which Medicare fueled a surge of spending in primary care; as we finished our residencies, prospective payment and sustainable growth rate [SGR] were being implemented."

- "We also adopt and adapt to the social movements of other generations. There was neither a rallying movement that we shared as a generation nor as medical professionals. The physicians of our era followed varied values and movements. Some of us followed the movements of social justice forged in the $60 \mathrm{~s}$ and $70 \mathrm{~s}$, others embraced the value of social change through technological innovation, while others followed the business model of health. For those of us that chose primary care, our leaders were those that started Family Medicine and primary care internal medicine. We bonded with their ideals of social justice, the promises and opportunities of improving health through work in primary care and heard of the frustrations of trying to change a health care system misaligned with achieving better health."

- "I continue to try and figure out if our generation is the forgotten generation. I wrote down a quote from my notes ... "Maybe the Millennials are the answer." Wow . . . skipped right over us. So where does that leave us? Midcareer . . . not old enough, not young enough, not nostalgic enough, not selfish enough, not narcissistic enough, not old school enough, not new school enough . . . what is my authentic, unique perspective? Am I holding on to the old way, am I helping shepherd in the new way? Either way, I sometimes feel like I continue to bob back and forth. So maybe that is our role? The transition generation?"

\section{Family Medicine and Midlife Crisis}

The sense of being caught between 2 movements continued into our professional identity as well. Many of us wrote about a conflict between 2 different visions of our chosen profession.

Some wrote about tension, stress, disillusionment, sometimes tempered by hope and enthusiasm for change but clearly idealism hardened by experience. While in part a sentiment of age and experience, several mentioned their "midlife" crisis; it was also clearly expressed as a reflection of the tension in family medicine between the ideal of relationship-based care and population and community health with the harsh realities of financial challenges, productivity, and unsympathetic health care delivery systems. 
- "Tension between holding on to the values of building and sustaining healing relationships and the demands of productivity focus and an increasing complexity of care within more complex systems."

- "Keystone was hard for me. It embraced many of the things that I love about medicine and reflected value for how I practice. It offered hope from young physicians and patients. But, I struggled to find nuggets of ideas, strategies, for moving forward."

- "When I think of Keystone, I think of how inspired and instantly conflicted I felt at the same time. I am inspired by the experiences of FM [family medicine] that many [in the] Baby Boomer generations have had and continue to have. I feel like I belong in their generation. I identify with the work ethic and passion and the concept that work is not a job, but an exciting adventure and honored profession. I identify with concepts of value and recognition as being primary drivers of satisfaction in my career, but really in life. I love hearing the stories of the country family doctor that would eat, sleep, and breathe their job. But I am conflicted because I also feel the pull of consumerism and technology and alternative types of healing relationships that do not need to be face to face. I sometimes want people to stop telling their nostalgic stories of how great it was to be a family doctor. I want to hear how great it is now. I do understand and actually greatly desire a better work-life balance, yet I am critical of the Millennials who demand it. I work for a large health care system that is getting primary care completely wrong, yet it is the only model that is viable in our region."

- "My experience is about helping patients understand they have choices: that treatments have benefits and risks, that weighing risks and benefits is important, but that few choices are final and we can make changes if first choices are not working well. I am increasingly challenged by volume-driven appointment times and discouraged by lack of value/attention given to continuity. I am alarmed by the aggressive overtreatment by some of our subspecialty colleagues, and save the names of those who respect patients, evidence, and who communicate well with me."
What Was This Generation's Experience of Keystone?

Keystone served to highlight our generation's internal conflict. The intergenerational representation at Keystone brought out the vivid sense of being "in between." But Keystone was also an affirmation of the power of relationship and brought many of us to a balanced appreciation of core values, experience, and our place in time.

- "Personally I define my life experience as a personal physician as being adaptable to changing systems. We were trained in the era of Clinton health reform, anticipated changes in payment models, consolidation of health delivery systems, promised primacy of primary care, the end of the solo practitioner, and frequent changes in leadership and clinic ownership. We saw primary care clinics change ownership 2 to 3 times in less than 5 years, while the people (docs and the patients) remained relatively unchanged. We learned that the constancy was the relationship between patient and doctor and what changed were the logos on the white coats, cards and clinic signs."

- "I think I live in a very idealistic place doing what I do. However, I would say that interacting with other FPs [family physicians] of our generation, I feel like we are settling into our stride, with enough years behind us to be confident and realistic, but still with the fire in our bellies to make things right in our health care system."

- "Like young adults, we recognize the humanity of those in the generation ahead of us and are humbled to recognize that we are also human as we assume mantels of leadership in primary care. We face the promise and practicalities of primary care and hope that we can use this latest wave of favor for primary care to move the model a little further. We have mixed emotions about the generation to follow, hoping that they can help us preserve the values of primary care as we move to population health, virtual relationships, and social-media enriched care."

- "Return to the core values of being a personal physician and the value to me, the patient, the community, and the health care system. I left Keystone reinvigorated and more resolute that the relationship between the patient and care provider is still the most important aspect of both why I am a physician and how I can improve the health of my community and health system." 
It is very likely that the angst voiced by this generation mirrors that of Generation II from the previous Keystone meeting. ${ }^{2}$ The similar themes of lack of balance, frustration, and feeling of being caught in between resonate and suggest that this is a common condition in this stage of professional life. While too easily labeled as a "midlife crisis," we observe the development from this mixture of emotions to a gradual affirmation of foundational values.

\section{Time and Place}

The Keystone conversation was initially focused on exploring the dimensions of time and place and how they apply so uniquely to family medicine. No other medical profession or discipline prides itself on longitudinality over life spans; understands and nourishes the length of time in relationship with patients; or uses time as a treatment, as a diagnostic tool, as a friend, and not necessarily as a nemesis.

Place is a parallel and just as critical dimension of family medicine. Much of our scholarship, folklore, and legend are embedded in place: the countryside, the small-town family doctor, the home visits, the inner city, the school and community. Indeed, population health is more dependent on geography than any other factor. ${ }^{3}$ We have special programs in rural health, urban underserved, refugee and immigrant communities, schools, and hospitals. $^{4}$

It is surprising how little we have studied time and place in relation to family medicine. The literature certainly appreciates continuity of care, definitions of the primary care relationship, and the singular importance of having a primary care physician. ${ }^{5}$ But other aspects remain untouched. What is common and different about family medicine in different neighborhoods and communities? How does a family physician's practice change over the course of decades? What is the meaning of a relationship over long periods of time?

On this last point Keystone delivered. Woven throughout the discussions of relationship were the implicit values of time and geographic community. Conversely, Keystone participants wrestled with asynchronous relationships in an age of social media-based, team-based, and technology-assisted relationships.

- "Keystone has helped me shape my view of how time, place, and relationships need to change in some ways and how they need to stay the same in other ways."

- "The power of person (relationships) and place impacted me deeply. Personally, certain key lessons stood out for advancing and distinguishing our specialty:

1. Build relationship-centered teams

2. Relationships give sustenance, a community of healing; relationships generate community solutions

3. Resilience and vulnerability

4. Boldness in your doctor; create a balance of boldness and tenderness: 'Be my doctor, my teacher, my coach. . .'

5. Context of place is changing; the doctor's office meets where the patient is: 'embrace places where needs are the greatest'

6. Find ways to always create joy in work"

\section{Reason for Hope}

From intergenerational angst and self-reflection, Keystone also engendered hope and reaffirmation. Often when family physicians gather there are common laments. More rarely-and Keystone was one of those times-there is a recognition of the gifts we receive and give, the blessing of being with people over time and place, the unique meaning in our work.

- "My favorite part of Keystone was simply witnessing fellow family physicians from all generations and all locations united in sharing the joys and challenges of family medicine. For a brief moment, I felt part of something bigger, more meaningful, something that would withstand the tests of time."

- "Perhaps if we fight for relationships, even over health, we can rally the people to join us in a renewed countercultural revolution.”

- "It just felt good to be around a lot of thoughtful people of multiple generations who were leaders and passionate about carrying on the tradition of doing the right thing for our patients. The commitment to being there for our patients was probably the strongest theme for me."

\section{Applying the Lessons of Keystone}

There are daily opportunities to promote the message of Keystone. Foremost are affirmations in our 
clinical work. These relationships that we have developed with our patients, now decades-long, are sustaining. Our insights into the tradecraft of being a personal physician are compelling and worth sharing. The personal connections are vital.

In our teaching we strive to demonstrate to students and residents the unique value of relationship. In our administrative work, research, and policy advocacy we have more opportunities that need to be uncovered. In these conversations, which often focus on quality and value, relationship is rarely discussed. Family physicians at these tables are best suited to remind others that relationships with our patients enable quality and value.

How do we advocate for the value of continuous healing relationships when maximizing value, Relative Value Units, or hand hygiene? How do we measure the personal and sustaining value of relationships in quality measures or research? Most important, how do we implement relationship into policy as we move into the quadruple aim? These are our challenges. But we have discerned opportunities. This generation's positions and experience are opening these doors.

- "I see us as doctors who value systems and are well-versed in notions of quality, evidence-based practice, and health care system realities, and well poised to lead and make change."

- "We have been in family medicine for about 20 years; certainly long enough to become cynical, long enough to dislike change! But not so long that we have forgotten idealism, new and radical ideas, the energy and perhaps the position to effect change?"

- "As we reach the peak years of productivity and expertise, we are making choices about change. We see the current changes in health care as the 1990s all over again. The consolidation of insurance, hospitals, and primary care delivery systems is increasing. Payment reform is again changing. The degree of uncertainty in the stability of practices and health systems is returning. The promise and opportunity for a more central role in health care delivery for primary care seems more possible than ever. We are rekindling our optimism for this change and tempering it tempered with our experience of the 90s and the disappointment of a retiring leadership. We are step- ping into the leadership roles in primary care and feeling the urgency of action in the face of opportunity and the need for courage and vision."

- "Keystone was rejuvenating as I felt I had time to revisit what is important to me with so many other brilliant and thoughtful thinkers and, perhaps, has enabled me to feel more confident in pursuing my passions. I found myself addressing over 40 medical students at a Gold Humanism Honor Society workshop on narrative medicine where I facilitated a 55-word story writing session. The remarkable 55-word stories that emerged from these first- to fourth-year medical students spoke to me that students do seek and find deep meaning in their relationships with patients."

- "I have been more mindful in my daily work, more 'present' during each patient encounter. My days seem to be richer and more rewarding."

\section{Conclusion}

For this generation, Keystone IV came at a midpoint in our lives and careers. The contrasts to earlier and subsequent generations were apparent and at times disturbing. The rose of family medicine idealism has shed its bloom, frosted by the realities of policy and practice. But we also have earned a deeper understanding of relationship with our patients and our daily work. Most significant, we are at a point in our careers where leadership and change are no longer distant aspirations but everyday realities. We bring Keystone and the central tenet of relationship to these opportunities.

\section{References}

1. Bliss E, Cadwallader K, Steyer TE, et al. A view from Cheyenne Mountain: Generation III's perspective of Keystone III. Ann Fam Med 2014;12:75-8.

2. Carmichael L, Schooley S. Is where we are where we were going? A dialogue of two generations. Fam Med 2001;33:252-8.

3. Murray CJL, Kulkarni SC, Michaud C, et al. Eight Americas: investigating mortality disparities across races, counties, and race-counties in the United States. PLoS Med 2006;3:e260.

4. Geyman JP, Hart LG, Norris TE, Coombs JB, Lishner DM. Educating generalist physicians for rural practice: how are we doing? J Rural Health 2000;16: 56-80.

5. Saultz JW. Defining and measuring interpersonal continuity of care. Ann Fam Med 2003;1:134-43. 